\title{
Correction to: Review of Transthyretin Silencers, Stabilizers, and Fibril Removal Agents in the Treatment of Transthyretin Cardiac Amyloid
}

\author{
Augustus Hough $^{1}$ (1) $\cdot$ Jessica Wearden ${ }^{2} \cdot$ Kristen de Almeida $^{3} \cdot$ Stephanie Kaiser $^{1}$
}

Published online: 28 September 2020

(C) Springer Science+Business Media, LLC, part of Springer Nature 2020

\section{Correction to: Current Cardiology Reports (2020) 22:106} https://doi.org/10.1007/s11886-020-01374-2

On page 2 of the original publication, in the section on TTR Silencers, dosing of patisiran in the APOLLO study was stated as being given every 3 months; this is inaccurate as patisiran was dosed every 3 weeks in the APOLLO study. The corrected sentence is presented below:

"Patisiran, as an intravenous infusion every 3 weeks, also slowed functional decline versus placebo in the APOLLO study; however, in contrast to inotersen, $56 \%$ of patients had an improvement in functional outcomes from baseline [14]."

Publisher's Note Springer Nature remains neutral with regard to jurisdictional claims in published maps and institutional affiliations.

The online version of the original article can be found at https://oi.org/ $10.1007 / \mathrm{s} 11886-020-01374-2$

Augustus Hough

Augustus.hough@va.gov

Jessica Wearden

Jessica.wearden@va.gov

Kristen de Almeida

KristenDe@baptisthealth.net

Stephanie Kaiser

Stephanie.Kaiser@va.gov

1 Clinical Pharmacy Specialist - Cardiology, West Palm Beach Veterans Affairs Medical Center, 7305 N. Military Trial, West Palm Beach, FL 33410, USA

2 PGY2 Cardiology Pharmacy Practice Resident, West Palm Beach Veterans Affairs Medical Center, West Palm Beach, FL, USA

3 Clinical Pharmacy Specialist - Cardiology, Baptist Hospital of Miami, 8900 N. Kendall Dr, Miami, FL 333176, USA 